\title{
Numerical analysis of different heating systems for warm sheet metal forming
}

\author{
J. M. P. Martins ${ }^{1}$ - J. L. Alves $^{2}$ • D. M. Neto ${ }^{1}$ - M. C. Oliveira ${ }^{1}$ - L. F. Menezes ${ }^{1}$
}

Received: 17 April 2015 / Accepted: 19 July 2015 / Published online: 2 August 2015

(C) Springer-Verlag London 2015

\begin{abstract}
The main goal of this study is to present an analysis of different heating methods frequently used in laboratory scale and in the industrial practice to heat blanks at warm temperatures. In this context, the blank can be heated inside the forming tools (internal method) or using a heating system (external method). In order to perform this analysis, a finite element model is firstly validated with the simulation of the direct resistance system used in a Gleeble testing machine. The predicted temperature was compared with the temperature distribution recorded experimentally and a good agreement was found. Afterwards, a finite element model is used to predict the temperature distribution in the blank during the heating process, when using different heating methods. The analysis also includes the evaluation of a cooling phase associated to the transport phase for the external heating methods. The results of this analysis show that neglecting the heating phase and a transport phase could lead to inaccuracies in the simulation of the forming phase.
\end{abstract}

\section{J. M. P. Martins}

joao.pmartins@dem.uc.pt

J. L. Alves

jlalves@dem.uminho.pt

D. M. Neto

diogo.neto@dem.uc.pt

M. C. Oliveira

marta.oliveira@dem.uc.pt

L. F. Menezes

luis.menezes@dem.uc.pt

1 CEMUC, Department of Mechanical Engineering, University of Coimbra, Polo II, Rua Luís Reis Santos, Pinhal de Marrocos, 3030-788 Coimbra, Portugal

2 MEMS, Microelectromechanical Systems Research Unit, University of Minho, Campus de Azurém, 4800-058 Guimarães, Portugal
Keywords Heating methods · Light-weight alloys · Warm forming conditions $\cdot$ Finite element method

\section{Introduction}

The automotive industry has made significant efforts in recent years to reduce the fuel consumption in passenger cars and consequently reduce the carbon dioxide $\left(\mathrm{CO}_{2}\right)$ emissions rates to fulfill the new environmental demands [1]. The adoption of light-weight materials, such as aluminium [2] and magnesium alloys [3], allows the weight reduction in body-in-white. Therefore, the actual trend in this industry consists in replacing traditional mild steels by light-weight materials. Although these alloys present high-strength-to-weight ratio and excellent corrosion resistance, the formability of these alloys at room temperature is considerably low when compared with low carbon steels, which limits its widespread application [4]. However, the formability can be significantly improved by warm forming, since the increase of temperature leads to a decrease in the material flow stress and improves the ductility [5].

Typically, the warm sheet metal forming process of lightweight alloys is performed in the temperature range of 200 to $350{ }^{\circ} \mathrm{C}$, below the recrystallization temperature to avoid microstructural changes. The behaviour of two $\mathrm{Al}-\mathrm{Mg}-\mathrm{Si}$ alloys during drawing was investigated by Ghosh et al. [6] at room and warm temperatures, concluding that the force-displacement evolution is strongly influenced by the blank temperature. Moreover, the formability (limiting drawing ratio) and ductility of these alloys is enhanced by the warm temperatures, as illustrated by Abedrabbo et al. [7]. Another advantage of warm forming processes is the decrease of the springback effects, resulting from the change of the stress state in the formed sheet [8]. The experimental and numerical study 
performed by Grèze et al. [9] shows that the stress gradient in a cylindrical cup wall decreases with the temperature, reducing the springback observed in the split-ring test. They conclude that the distribution of the hoop stress in the cup wall is the main factor influencing the springback mechanism in warm forming condition. In addition to the above-mentioned benefits, the stretcher lines arising in the AA5xxx series (Al-Mg alloys) due to the Portevin-Le Chatelier (PLC) effect vanish at warm temperatures, as highlighted in the experimental study performed by Coër et al. [10].

In comparison with the conventional sheet metal forming processes, the warm forming requires an additional stage to increase the temperature of the blank before the forming operation. Two distinct strategies can be adopted for the heating process: (1) generate a uniform (warm) temperature in the whole blank or (2) apply a gradient of temperatures in the blank, i.e., increase the temperature in some regions and cooling others [11]. An example of the former strategy has been recently proposed by Hung and Merklein [12] using a laser system for local heat treatment of the blank in order to enhance its formability. However, since this heating procedure requires a deep knowledge of the interaction between mechanical and thermal effects on formability, the concept commonly used in industry is still the uniform heating of the blank [13]. Concerning this simple strategy, the heating of the blank can be carried out using two different heating methods: (1) external heating in furnaces, induction systems or direct resistance systems and (2) internal heating by conduction through heated tools on the press. The systems used in the external heating can be classified by direct and indirect according to the heat transfer mechanism [14]. The conventional furnaces are the heating systems commonly employed by the industry due to its high production flexibility and availability. On the other hand, on a laboratory or R\&D scale the temperature of the blank is usually raised by internal heating by means of conduction with heated tools [15]. Nevertheless, this last procedure involves complex tool systems with high costs (electrical resistance heaters inserted at different locations in the tool), and can increase substantially the process lead time, eliminating the high productivity rates characteristic of the metal forming processes.

The temperature distribution in the blank immediately before the forming operation is a key point for the success of the warm sheet metal forming processes [6]. However, this heating stage is typically overlooked in the numerical modelling of the process, as well as the cooling of the blank that occurs during its transport to the press, in case of external heating [16]. In fact, the temperature of the blank is commonly assumed uniform at the beginning of the forming stage in the finite element analysis. Therefore, this study intends to improve the finite element modelling of the warm sheet metal forming processes by taking into account both the initial heating stage and the subsequent transfer period (air cooling), when considering external heating systems. In this context, the algorithm for the thermal analysis was implemented in the finite element code DD3IMP [17], which has been specifically developed to simulate sheet metal forming processes. Its key feature is the use of a fully implicit algorithm of NewtonRaphson type to solve, within a single iterative loop, the nonlinearities related with both the mechanical behaviour and the frictional contact [18].

The comparison between the different heating methods frequently used in warm forming processes is presented in this work. The transient thermal problem (blank heating) is analysed with the finite element method considering both conduction and convection mechanisms. The developed finite element code and the numerical model are validated with experimental results from a tensile specimen heated by Joule's effect (Gleeble system). Moreover, the heating stage for the warm sheet metal forming of an automotive B-pillar is presented in detail, comparing different heating methods through finite element simulation.

\section{Heating methods}

This section presents a review of different heating methods typically adopted in warm sheet metal-forming processes, both in laboratory scale as well as in industrial practice.

\subsection{Furnaces}

The heating process through furnace is the conventional method used in industry, where the heat can be generated either by fossil fuels or electricity [19]. The procedure consists in loading the blank into the furnace in order to raise its temperature up to the warm forming temperature. Since the blank is heated mainly by convective flow from the heat source, the furnaces are slow heating systems. Indeed, the final temperature of the blank is dictated by the exposure time and the temperature of the furnace. Since the ratio between exposed surface and volume is very high in metallic sheets, the temperature gradients between the core and the sheet surface are negligible.

The heating system adopted by Takuda et al. [20] in the warm deep drawing of an aluminium alloy $5182-\mathrm{O}$ is the furnace. The forming tools (die and blank-holder) are heated together with the blank sheet until $250^{\circ} \mathrm{C}$ and then assembled into the press. This experimental procedure allows to avoid heat losses to the tools during the forming stage. The metallography of the austenitic stainless steel 304 after warm deep drawing was studied by Lade et al. [21]. They also heated the blank and the die using a furnace to carry out warm forming tests at temperatures on the range between 150 and $300{ }^{\circ} \mathrm{C}$. The mechanical characterisation for warm forming temperature of the magnesium AZ31 alloy sheet for was performed by Koh et al. [22] using a numerical inverse approach. The deep 
drawing of a cylindrical cup was the example selected, where both the blank and the forming tools, except the punch, were heated in an external furnace until reaching $280^{\circ} \mathrm{C}$. Due to the heat loss to the environment during the moving and setting, the blank temperature decreases about $15^{\circ} \mathrm{C}$ in $5 \mathrm{~s}$. The mechanical behaviour of three commercial magnesium sheet alloys was studied by Krajewski [23] at warm temperatures. The blanks were heated in a furnace on the range of temperatures between 200 and $400{ }^{\circ} \mathrm{C}$. Its temperature was measured immediately before the forming process and was about $50{ }^{\circ} \mathrm{C}$ cooler than the temperature at the furnace exit, highlighting the heat losses to the environment during the movement of the blank to the press. In order to optimize the warm forming process in terms of production robustness and costs, Harrison et al. [16] present a non-isothermal method. Only the blank (5182-O aluminium alloy) was heated inside a furnace using an exposure time of $180 \mathrm{~s}$ to reach the warm forming temperature. After the heating process, the blank was moved to the press using a robot, consuming about $15 \mathrm{~s}$ in this operation. The heat losses for the tools were not avoided, in fact, they were intentional in order to obtain a non-isothermal condition after the forming stage.

\subsection{Induction heating}

The application of an alternating current in an induction coil generates a magnetic field, which induces eddy currents in electrically conductive objects located in the vicinity of the coil (Faraday's law). Consequently, this produces heat as a result of the Joule's effect [13]. The frequency and the intensity of the induced current, as well as the material properties (specific heat, magnetic permeability and electrical resistivity) define the heating rate of the body. Since the aluminium alloys present low electrical resistivity when compared with steel alloys, they require a longer heating stage to attain the same temperature [24]. Since the current density decreases exponentially towards the body centre, leading to a non-uniform current distribution within the body, the so called skin-effect is directly related with this heating system. This effect can be relieved by decreasing the current frequency. The thermomechanical properties of the aluminium alloy $7000-\mathrm{T} 4$ were evaluated by Codrington et al. [25] at 260 and $480{ }^{\circ} \mathrm{C}$ using a new induction heating apparatus developed by the authors. Takuda et al. [26] studied the flow stress evolution of a commercial magnesium alloy AZ31 at warm temperatures adopting an induction system to achieve the required temperatures. The mechanical properties of the magnesium alloy AZ31B at different temperatures and strain rates were investigated by Pellegrini et al. [27] using an induction heating system. The temperature range between 200 and $300{ }^{\circ} \mathrm{C}$ was selected and a constant heating rate of $3{ }^{\circ} \mathrm{C} / \mathrm{s}$ was applied. In order to assure a uniform temperature field, the specimen was maintained at this temperature during $120 \mathrm{~s}$.

\subsection{Direct resistance heating}

In case of the direct resistance heating, the blank is connected in series with a power source. The material resistance to the passage of current produces heat by Joule's effect. The heating rates are directly related with the current intensity and the material properties. In fact, materials with higher electric resistivity present larger resistance to the current flow, leading to a more efficient heating procedure. The main limitation of this heating system is related with its range of application, which is restricted to sheets with constant cross-section. The variation of the cross-sectional area in the current direction yields a nonuniform temperature along the blank, i.e., the temperature becomes higher for small cross-sectional areas and lower for large cross-sectional areas, respectively [28]. Mori et al. [29] presented a study concerning warm and hot stamping process using resistance heating. The experimental work was developed in a new apparatus which was developed by the authors, consisting in a press coupled with a direct resistance heating system. They achieved a temperature of $850{ }^{\circ} \mathrm{C}$ in $1.5 \mathrm{~s}$. Furthermore, they synchronised the press with the heating system to minimizing the heat loses, allowing to accomplish the forming operation $0.2 \mathrm{~s}$ after the end of the heating phase. Since the mechanical contact between the sheet and the electrode is not perfect and homogeneous, the generated temperature field is non-uniform in the contact area. This heating system provides high heating rates using a simple apparatus, being adequate for characterisation of materials at elevated temperatures. Das et al. [30] investigated the mechanical properties of a magnesium alloy AZ31 at warm temperature, using a Gleeble 3800 thermomechanical simulator. The tensile specimens were heated by direct resistance to $200{ }^{\circ} \mathrm{C}$ and were held at this temperature during $1 \mathrm{~min}$. The same thermo-mechanical simulator was used by Coër et al. [31] to study the influence of temperature on the mechanical behaviour of an aluminium alloy AA5754-O during plastic deformation. Ghosh et al. [6] presented a description of the behaviour of two $\mathrm{Al}-\mathrm{Mg}-\mathrm{Si}$ alloys during drawing and post drawing. The equipment used to perform the tensile tests was also a Gleeble testing machine.

\subsection{Heating by conduction with heated forming tools}

The heating of a blank with pre-heated tools is typically used in the warm deep drawing at laboratory scale. In this case, both the die and the blank-holder are pre-heated to the warm forming temperature [4], while the blank is heated by contact conduction with the tools when it is clamped between the blank-holder and die. The tools are commonly heated by electric heating elements and the location of these elements depends on the set-up used. The main advantage of this process is to avoid the loss of heat during the transport stage, since the blank is already in the position to be formed [32]. However, a large amount of material volume (tools) has to be heated and 
the time required to achieve a uniform temperature of the blank might be high. This heating method is commonly used for attaining non-isothermal distributions on the blank [33]. Lee et al. [34] have studied the formability of an AZ31 magnesium sheet by experimental and numerical analysis. The square cup drawing is performed at various temperatures using a tooling system heated by cartridge heaters. Laurent et al. [8] focused on the warm deep drawing of an AA5754$\mathrm{O}$ aluminium alloy, presenting a new experimental set-up designed to perform cylindrical cup forming tests. In this case, the blank was heated by thermal contact with the die and the blank-holder during $500 \mathrm{~s}$ to guarantee a uniform temperature in the blank.

\section{Finite element method}

\subsection{Heat transfer analysis}

The differential equation of heat conduction, often called heat equation, can be derived from the law of conservation of energy (first law of thermodynamic) applied to a continuous medium with arbitrary volume $\left(V \in \mathbb{R}^{3}\right)$ bounded by a closed surface $S$. The solution of the heat equation gives the temperature distribution of the arbitrary volume with respect to time and can be expressed as follows:

$\rho c \frac{\partial T}{\partial t}+\operatorname{div}\left(\mathbf{q}_{\mathrm{k}}\right)=\dot{q}$,

where $\rho$ and $c$ represent the specific mass and the specific heat of the continuous medium, respectively. The vector $\mathbf{q}_{\mathrm{k}}$ represents the conduction heat flux and $\dot{q}$ is the energy rate generation per unit of volume. The heat conduction flux is defined by the Fourier law of conduction, as follows:

$\mathbf{q}_{\mathrm{k}}=-\operatorname{kgrad}(T)$,

where $\mathbf{k}$ is the conductivity tensor. Combining Eq. (1) and (2), the relation governing the heat conduction can be written as:

$\rho c \frac{\partial T}{\partial t}=\operatorname{div}[\operatorname{kgrad}(T)]+\dot{q}$.

The classical boundary heat exchanges conditions comprise the heat transfer modes of convection and radiation. To model the convection boundary condition it is necessary to know the convection coefficient $h_{\mathrm{c}}$ and the exterior temperature $T_{\infty}$ in order to define the convection heat flux as follows:

$q_{\mathrm{conv}}=h_{\mathrm{c}}\left(T-T_{\infty}\right)$.

The radiation boundary condition term is defined also based on a heat flux:

$q_{\mathrm{rad}}=h_{\mathrm{r}}\left(T-T_{\mathrm{sur}}\right)$, in which the $h_{r}$ is defined by:

$h_{\mathrm{r}}=\varepsilon \sigma\left(T^{2}+T_{\text {sur }}^{2}\right)\left(T+T_{\text {sur }}\right)$,

where $T_{\text {sur }}$ is the surrounding temperature, $\varepsilon$ is the emissivity of the surface and $\sigma$ is the Stefan-Boltzmann constant.

\subsection{Numerical implementation}

\subsubsection{Finite element discretization}

Applying the principle of virtual temperatures to the strong form [35], the general heat equation can be written in the weak form as follows:

$\int_{V} \delta T \rho c \dot{T} d V+\int_{V} \operatorname{grad}(\delta T) \cdot[\mathbf{k} \cdot \operatorname{grad}(T)] d V+\int_{S} \delta T h_{\text {conv }} T d S+\int_{S} \delta T h_{\mathrm{r}} T d S=$

$\int_{V} \delta T \dot{q} d V+\int_{S} \delta T h_{\text {conv }} T_{\infty} d S+\int_{S} \delta T h_{\mathrm{r}} T_{\text {sur }} d S$.

The weak form is obtained by multiplying the governing Eq. (3) and the convection and radiation boundary conditions (Eqs. (4) and (5)) by an arbitrary virtual temperature distribution $\delta T$ and integrating over the domains on which they hold. According with this principle, $T$ is the solution of the temperature distribution in the body if and only if Eq. (7) holds for any arbitrary virtual temperature distribution $\delta T$ that is continuous and satisfies the boundary conditions.

The finite element method involves the division of the volume $V$ under consideration into finite elements. The temperature inside a finite element is interpolated using the shape functions and the temperatures at nodes, which can be approximated by:

$$
\begin{array}{ll}
\mathbf{T}(x, t)=\mathbf{N}(x) \mathbf{T}(t) & \text { for } \left.V \forall t \in] 0, t_{\mathrm{f}}\right], \\
\mathbf{T}(x, t)=\mathbf{N}_{\mathrm{s}}(x) \mathbf{T}(t) & \text { for } S \forall t \in]\left(0, t_{\mathrm{f}}\right],
\end{array}
$$

where $t_{\mathrm{f}}$ denotes the final instant of the process. $\mathbf{N}(x)$ and $\mathbf{N}_{\mathrm{s}}(x)$ are matrices containing the shape functions associated with the volume and the surface of the body, respectively. Thus, the discretized finite element equations for heat transfer problems can be written as follows:

$\mathbf{C} \dot{\mathbf{T}}+\left(\mathbf{K}_{\text {cond }}+\mathbf{K}_{\text {conv } / \mathrm{rad}}\right) \mathbf{T}=\mathbf{Q}+\mathbf{f}$

where $\mathbf{C}$ is the thermal capacity matrix and $\mathbf{K}_{\text {cond }}$ and $\mathbf{K}_{\text {conv/rad }}$ are the conductivity and the convection/radiation stiffness matrices, respectively. $\mathbf{Q}$ and $\mathbf{f}$ are the vectors of heat generation and heat fluxes on the surface, respectively. These matrices and vectors can be expressed as:

$\mathbf{C}=\int_{V} \mathbf{N}^{\mathrm{T}} \rho c \mathbf{N} d V$ 


$$
\begin{aligned}
& \mathbf{K}_{\text {cond }}=\int_{V} \mathbf{M}^{\mathrm{T}} \mathbf{k} \mathbf{M} d V \\
& \mathbf{K}_{\text {conv } / \text { rad }}=\int_{S} \mathbf{N}_{\mathrm{s}}^{\mathrm{T}} h_{\text {conv }} \mathbf{N}_{\mathrm{s}} d S+\int_{S} \mathbf{N}_{\mathrm{s}}^{\mathrm{T}} h_{\mathrm{r}} \mathbf{N}_{\mathrm{s}} d S \\
& \mathbf{Q}=\int_{V} \mathbf{N}^{\mathrm{T}} \dot{q} d V \\
& \mathbf{f}=\int_{S} \mathbf{N}_{\mathrm{s}}^{\mathrm{T}} h_{\text {conv }} \mathbf{T}_{\infty} d S+\int_{S} \mathbf{N}_{\mathrm{s}}^{\mathrm{T}} h_{\mathrm{r}} \mathbf{T}_{\mathrm{r}} d S
\end{aligned}
$$

where $\mathbf{M}=\operatorname{grad}(\mathbf{N})$. The vector of internal heat generation (Eq. (13)) comprises the heat generated in the volume $V$ by different sources such as electrical resistance heating or induction [36].

\subsubsection{Time integration method}

In transient heat conduction analysis, Eq. (9) must be integrated over the time. Different time integration methods based on one or more time steps are available [37]. In this work, the method adopted is a one-time step method, often named the generalized trapezoidal method [38]. This time integration method can be deduced from the Taylor's expansion series, by neglecting the second and higher-orders terms and introducing a time weighting factor $\alpha$ varying between 0 and 1 . Thus, the temperature field at instant $t+\Delta t$ is obtained using the following equation:

$\mathbf{T}_{t+\Delta t}=\mathbf{T}_{t}+\left[\alpha \dot{\mathbf{T}}_{t+\Delta t}+(1-\alpha) \dot{\mathbf{T}}_{t}\right] \Delta t$.

Applying the definition of the trapezoidal method into Eq. (9), the following expression is obtained:

$$
\begin{aligned}
& {\left[\frac{1}{\Delta t} \mathbf{C}+\alpha\left(\mathbf{K}_{\text {cond }}+\mathbf{K}_{\text {conv/rad }}\right)\right] \mathbf{T}_{t+\Delta t^{-}}\left[\frac{1}{\Delta t} \mathbf{C}-(1-\alpha)\left(\mathbf{K}_{\text {cond }}+\mathbf{K}_{\text {conv/rad }}\right)\right] \mathbf{T}_{t}=} \\
& (1-\alpha) \mathbf{Q}_{t}+\alpha \mathbf{Q}_{t+\Delta t}+(1-\alpha) \mathbf{f}_{t}+\alpha \mathbf{f}_{t+\Delta t} .
\end{aligned}
$$

Depending on the value selected for $\alpha$, the generalized trapezoidal method takes the form of well-known time integration methods such as, Euler forward method $(\alpha=0)$, Crank Nickolson method $\left(\alpha=\frac{1}{2}\right)$, Galerkin method $\left(\alpha=\frac{2}{3}\right)$ and Euler backward method $(\alpha=1)$ [39].

Only the Euler backward is known to be unconditionally stable for non-linear thermal problems [40], i.e. starting from a thermal equilibrium state at time $t$, it reaches a thermal equilibrium state at time $t+\Delta t$. Therefore, assuming $(\alpha=1)$, Eq. (16) takes the following form:

$$
\left[\frac{1}{\Delta t} \mathbf{C}+\left(\mathbf{K}_{\mathrm{cond}}+\mathbf{K}_{\mathrm{conv} / \mathrm{rad}}\right)\right] \mathbf{T}_{t+\Delta t}-\left(\frac{1}{\Delta t} \mathbf{C}\right) \mathbf{T}_{t}=\mathbf{Q}_{t+\Delta t}+\mathbf{f}_{t+\Delta t},
$$

which is typically solved with the Newton-Raphson iterative method, guaranteeing the equilibrium in all increments. The non-linear system presented in Eq. (17) can be rewritten in a simplified way, as follows:

$\mathbf{K}_{\mathrm{G}} \mathbf{T}_{t+\Delta t}-\mathbf{P}_{t+\Delta t}=\mathbf{R}_{t+\Delta t}$,

where $\mathbf{K}_{G}$ and $\mathbf{P}_{t+\Delta t}$ assume the following form:

$\mathbf{K}_{\mathrm{G}}=\frac{1}{\Delta t} \mathbf{C}+\left(\mathbf{K}_{\mathrm{cond}}+\mathbf{K}_{\mathrm{conv} / \mathrm{rad}}\right)$,

$\mathbf{P}_{t+\Delta t}=\left(\frac{1}{\Delta t} \mathbf{C}\right) \mathbf{T}_{t}+\mathbf{Q}_{t+\Delta t}+\mathbf{f}_{t+\Delta t}$,

and $\mathbf{R}_{t+\Delta t}$ is the residue originated by the updating of $\mathbf{K}_{\mathrm{G}}$ and $\mathbf{P}_{t+\Delta t}$ with the temperature distribution for the instant $t+\Delta t$.

The application of the Newton-Raphson iterative scheme involves the evaluation of the linearized system of Eq. (18), which is expressed by:

$$
\begin{aligned}
& \left(\frac{1}{\Delta t} \mathbf{C}_{t+\Delta t}^{i}+\mathbf{K}_{t+\Delta t}^{i}\right) \Delta \mathbf{T}_{t+\Delta t}^{i+1} \\
& =\left(\frac{1}{\Delta t} \mathbf{C}_{t+\Delta t}^{i}\right) \mathbf{T}_{t}+\mathbf{Q}_{t+\Delta t}^{i} \\
& \quad+\mathbf{f}_{t+\Delta t}^{i}-\left(\frac{1}{\Delta t} \mathbf{C}_{t+\Delta t}^{i}+\mathbf{K}_{t+\Delta t}^{i}\right) \mathbf{T}_{t+\Delta t}^{i},
\end{aligned}
$$

where the superscript $i$ and the subscript $t$, which follow the vectors and matrices, represent the iteration number and the configuration where the vectors and matrices are calculated, respectively. The matrix $\mathbf{K}$ is given by:

$\mathbf{K}=\mathbf{K}_{\text {cond }}+\mathbf{K}_{\text {conv } / \text { rad }} \cdot$

The adoption of a fully implicit method (NewtonRaphson) presents the drawback of excessive computational cost, contrasting with explicit and semi-implicit methods such as Euler's method, Crank Nickolson's method and Galerkin's method. However, implicit algorithms guarantee the equilibrium in all increments, leading to stable results. It is recognized that most of the time spent by fully implicit methods is related with the iterative cycle [41]. Nevertheless, the computation time of the implicit method can be reduced using an initial guess close to the solution. Therefore a prediction/ correction algorithm type is proposed in this work to solve the non-linear heat problem. In the prediction phase, an explicit/semi-implicit algorithm $(\alpha<1)$ is used to solve the thermal problem combined with an $r_{\text {min }^{-}}$ strategy to control the size of the time increment [42, 43]. The obtained solution is used to define the initial guess for the correction phase $(\alpha=1)$. The predictor/ corrector algorithm is presented in Table 1. 
Table 1 Predictor/corrector algorithm

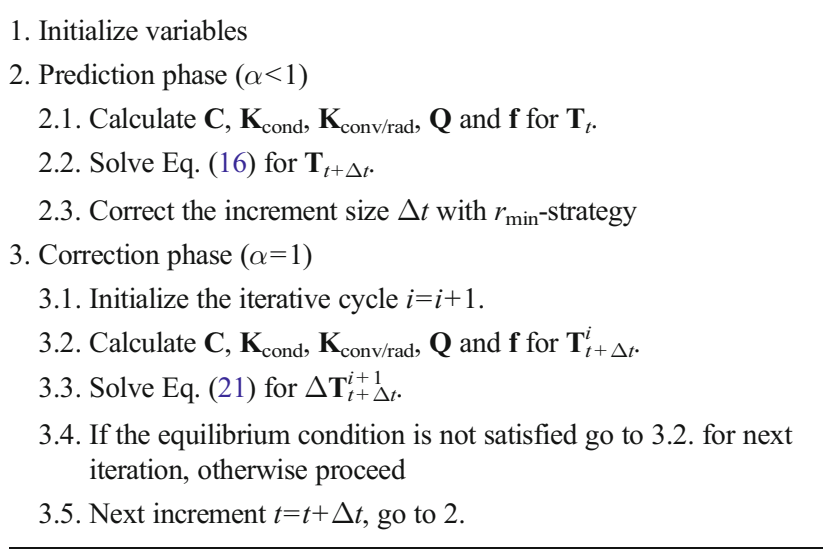

\subsection{Numerical modelling of the heating systems}

The conventional furnaces use a fluid medium (usually air) to heat the blank. The principal mechanism of heat transfer to the body in this case is the convection, while the radiation assumes a negligible role in the process. However, the accurate simulation of this heating process needs to take into account radiation through a combined radiation-convection heat transfer coefficient $h_{\text {conv/rad }}$ [43]. Therefore, in this study, the combined coefficient is adopted, where the fluxes can be determined using:

$q_{\mathrm{conv} / \mathrm{rad}}=\left(h_{\mathrm{conv}}+h_{\mathrm{r}}\right)\left(T-T_{\infty}\right)=h_{\mathrm{conv} / \mathrm{rad}}\left(T-T_{\infty}\right)$.

The heating mechanism in the direct resistance process is the Joule's effect. Its numerical modelling is performed using an internal heat generation per unit volume, which is accomplished in the vector of heat sources $\mathbf{Q}$ (Eq. (13)). This heat source can be defined through the Joule's first Law, given by:

$\dot{q}=\frac{I^{2} R}{V}$,

where $V$ is the volume of the body, $I$ is the current intensity and $R$ is the electric resistance of the body's material.

The simulation of an induction heating system has to take into account the inherent shortcoming of non-uniform heating due to the so-called skin-effect. In this system the current flow is concentrated in the vicinity of the surface. The thickness of this region, called skin depth, is dependent of the electric current frequency and can be calculated from the relation [44]:

$\delta(f)=\sqrt{\frac{\rho_{\mathrm{r}}}{\pi f \mu_{\mathrm{r}} \mu_{0}}}$

where $f$ is the frequency, $\rho_{\mathrm{r}}$ is the resistivity of the body's material, $\mu_{\mathrm{r}}$ is the magnetic permeability of the material and $\mu_{0}=4 \pi \times 10^{-7} \mathrm{H} / \mathrm{m}$ is the constant called permeability of the free space. The modelling of this heating system requires the definition of the skin depth region, in order to introduce the internal heat generation in that region. The heat generation rate can be evaluated from Eq. (24) since the heat is generated by Joule's effect. Nevertheless, this equation needs to be affected by a factor of 0.87 , since it is estimated that only $87 \%$ of the induced current is located in this region [45].

The heat exchange between the forming tools and the blank involves complex thermal interactions. Since the contact between bodies is not perfect, a difficult aspect to model this process is to define the fraction of the surface effectively in contact. Typically the heat transfer by contact is modelled assuming a boundary condition analogous to convection, defining a conductance heat transfer coefficient $h_{\text {cond. }}$. Thus the heat fluxes in the contact area can be determined with the following equation:

$q_{\text {cond }}=h_{\text {cond }}\left(T-T_{\infty}\right)$,

where $T_{\infty}$ represents the temperature of the tool. The process of heating by conduction with heated forming tools is modelled in this study by considering a heat flux between the heated tools and the blank.

\section{Numerical examples}

This section presents two examples of metallic sheets heated by different heating systems. The first example involves the direct resistance heating of an aluminium alloy sheet, procedure typically used in thermo-mechanical testing systems. The numerical results obtained with the developed finite element code are compared with available experimental data. The second example comprises the numerical simulation of the heating phase required for the warm sheet metal forming processes. The different heating methods presented in Section 2 are numerically compared considering an automotive B-pillar as example.

\subsection{Direct resistance heating using a Gleeble system}

The Gleeble heating system was selected for the first example due to its simplicity and widespread application in studies devoted to warm forming. The numerical simulation of the temperature evolution and distribution on the specimen heated with a Gleeble 3500 system is presented. The obtained numerical results are compared with the experimental ones presented by Coër et al. [31]. They have used this heating system to perform tensile tests of an aluminium alloy 5754-O sheet at warm temperatures (see Fig. 1a). The geometry of the specimen (1 mm of thickness) used in the experimental set-up is presented in Fig. 1b. The specimen was heated in the experimental procedure until attaining $200{ }^{\circ} \mathrm{C}$ (central point- $\mathrm{TC} 1$ ), which corresponded to a heating time of about $13.4 \mathrm{~s}$. 
Fig. 1 Direct resistance heating using a Gleeble system: (a) experimental set-up; (b) geometry of the specimen $\left(L_{0}=40 \mathrm{~mm}, b=\right.$ $10 \mathrm{~mm}$ and $\left.L_{c}=80 \mathrm{~mm}\right)$

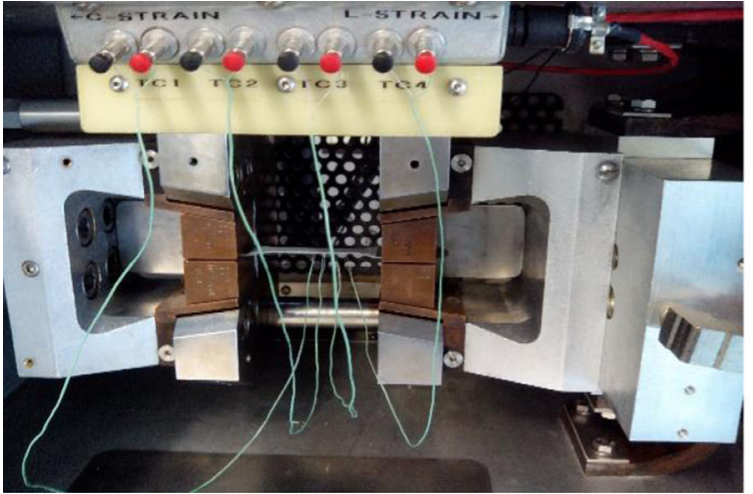

(a)

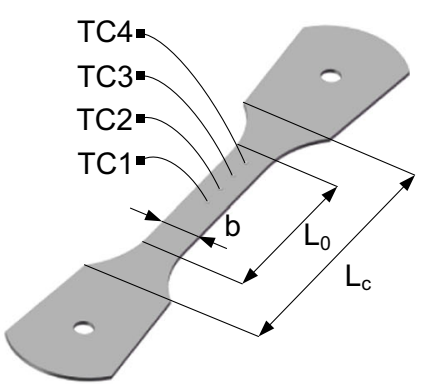

(b)
Due to geometric and material symmetry conditions (Fig. 1), only one eighth of the model was simulated. The tensile specimen and the copper grips were discretized as a single body using isoparametric eight-node linear hexahedral finite elements, as shown in Fig. 2. The distinction between the specimen and the grips was performed in the numerical model assigning different thermal properties to each region. The temperature of the specimen was recorded in the experimental set-up using four thermocouples equally spaced $(6 \mathrm{~mm})$ along the specimen axis, as illustrated in Fig. $1 \mathrm{~b}$. The finite element mesh was generated in order to create nodes in the same positions (see Fig. 2). The Gleeble testing system heats the sheet by direct resistance using an electrical control scheme, which changes the applied current intensity to achieve a target temperature in the centre of the specimen, measured with a thermocouple (TC1 in Fig. 1b), for the time designated by the user [46]. The numerical modelling of the heat generated by electrical current was carried out in this study through an energy rate generation in the volume of the specimen (Eq. (13)), which was evaluated in each increment to try to guarantee a constant heating rate. The numerical temperature $T^{\mathrm{c}}$, evaluated in the position of the thermocouple $\mathrm{TC} 1$, was compared with a pre-defined temperature $T^{\mathrm{p}}$, in order to define the vector of heat generation using the predictor/corrector algorithm (Table 2). This pre-defined temperature $T^{\mathrm{p}}$ was calculated in each time instant, based on the prescribed heating rate.

The grips of the Gleeble system were water-cooled during the heating process. In the present study, the heat loss to the grips was modelled applying a high convection coefficient in the top surface of the grip, which was a procedure also adopted by Kardoulaki et al. [46]. The value of the convection coefficient used was $1,000 \mathrm{~W} / \mathrm{m}^{2} /{ }^{\circ} \mathrm{C}$, with a temperature of $22{ }^{\circ} \mathrm{C}$ for the $T_{\infty}$ in Eq. (4). Additionally, the heat loss by convection to the environment was taken into account using a convection coefficient of $40 \mathrm{~W} / \mathrm{m}^{2} /{ }^{\circ} \mathrm{C}$ and air temperature of $22{ }^{\circ} \mathrm{C}$, as suggested in [26]. The thermal properties of the aluminium alloy 5754-O and the copper grips were assumed as temperature-independent and isotropic and are given in Table 3.
Fig. 2 Finite element model of the tensile specimen and the grip used in the Gleeble system (one eighth)

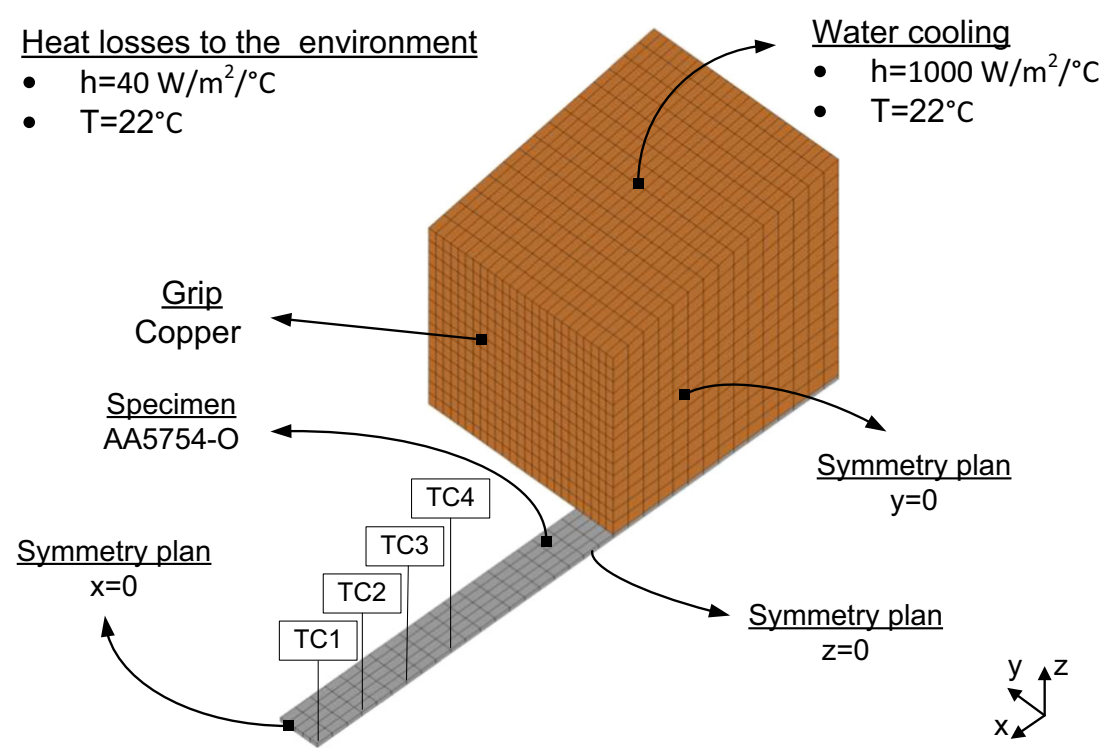


Table 2 Algorithm for Gleeble heating system simulation

1. Initialize variables $\mathbf{T}_{t}=\mathbf{T}^{\text {initial }}$ and $t=0 s$.

2. Prediction phase

2.1. If $\left\|T^{\mathrm{p}}-T^{\mathrm{c}}\right\|>0$ then

Calculate $\dot{q}_{t+\Delta t}=\rho c \frac{\left(T^{\mathrm{p}}-T^{\mathrm{c}}\right)}{} \Delta t$

End if

2.2. Build and solve Eq. (16) for $\mathbf{T}_{t+\Delta t}$.

3. Correction phase

3.1. If $\left\|T^{\mathrm{p}}-T^{c}\right\|>$ tolerance then

Calculate $\Delta \dot{q}_{t+\Delta t}^{i+1}=\rho c \frac{\left(T^{\mathrm{p}}-T^{\mathrm{c}}\right)}{t} \Delta t$

Calculate $\dot{q}_{t+\Delta t}^{i+1}=\dot{q}_{t+\Delta t}^{i}+\Delta \dot{q}_{t+\Delta t}^{i+1}$

End if

3.2. Build and solve Eq. (21) for $\Delta \mathbf{T}_{t+\Delta t}^{i+1}$.

3.3. If the equilibrium condition is not satisfied got to 3.1 for next iteration, otherwise proceed

3.4. Next increment $t=t+\Delta t$, go to 2 .

The temperature distribution on the specimen, as well as on the grips, is presented in Fig. 3. The water-cooling of the grips leads to a thermal gradient in the specimen caused by the heat removed from the grips. In fact, the temperature of the grips is approximately uniform $\left(22^{\circ} \mathrm{C}\right)$ during the heating process of the specimen. The comparison between the experimental temperatures measured with the thermocouples and the numerical prediction is presented in Fig. 4. The numerical results are in good agreement with the experimental ones, particularly for the positions related with the thermocouples TC1 and TC2. Moreover, the numerical results can be exactly fitted by a quadratic equation, as shown in Fig. 4, which is not observed in the experimental data. This difference can results from the influence of temperature in the material thermal properties, which was not taken into account in this model.

The transient thermal evolution of the specimen, recorded using four thermocouples and predicted with the finite element model is presented in Fig. 5. The temperature evolution is approximately linear for all points analysed, i.e., presents a constant heating rate. Besides, the numerical results are in good agreement with the experimental ones, in particular for the thermocouples TC1 and TC4. In order to highlight the

Table 3 Thermal properties of the specimen and grips materials $[8,50]$

\begin{tabular}{ll}
\hline Sepcimen material & AA5754-O \\
\hline Density $\left(\mathrm{kg} / \mathrm{m}^{3}\right)$ & 2,700 \\
Specific heat $\left(\mathrm{J} / \mathrm{kg} /{ }^{\circ} \mathrm{C}\right)$ & 900 \\
Conductivity $\left(\mathrm{W} / \mathrm{m} /{ }^{\circ} \mathrm{C}\right)$ & 220 \\
Grips material & Copper \\
Density $\left(\mathrm{kg} / \mathrm{m}^{3}\right)$ & 8,800 \\
Specific heat $\left(\mathrm{J} / \mathrm{kg} /{ }^{\circ} \mathrm{C}\right)$ & 400 \\
Conductivity $\left(\mathrm{W} / \mathrm{m} /{ }^{\circ} \mathrm{C}\right)$ & 300 \\
\hline
\end{tabular}

difference between them, a detail view of the global evolution is also presented in Fig. 5, for the last $3 \mathrm{~s}$. The maximum difference between them is about $3.5{ }^{\circ} \mathrm{C}$, which occurs in the thermocouple TC3 for the last instant (increment).

\subsection{Heating phase of an automotive B-pillar}

The comparison between the four heating methods mentioned in Section 2 for the warm sheet metal forming was applied to an automotive B-pillar. This example was proposed by Audi as benchmark in the conference Numisheet 2008 [47]. The blank geometry was adapted for the present study to obtain a constant cross-sectional area, allowing the use of direct resistance heating method. The dimensions of the rectangular blank are $1,090 \times 400 \times 1.95 \mathrm{~mm}$, as shown in Fig. 6 . The blank has been discretized with eight-node hexahedral finite elements, considering 100 finite elements in the length direction and 40 elements in the width direction. Concerning the number of layers of finite elements through the thickness, it was dictated by the induction heating system, which requires the definition of the skin depth for the sheet. Thus, the blank thickness was divided in 6 finite elements, leading to a structured mesh with 24,000 finite elements, where the element size was adjusted according to the thickness of the skin depth region. The aluminium alloy 5754-O was the material adopted in this study, with the thermal properties presented in Table 3.

The same potency of $32 \mathrm{~kW}$ was used for all heating systems. Accordingly, the convection heat transfer coefficient was calculated for the furnace, while the internal heat generation was determined for both the direct resistance and the induction system. In case of heating the blank with the tools, a conductance coefficient of $1,400 \mathrm{~W} / \mathrm{m}^{2} /{ }^{\circ} \mathrm{C}[20]$ was adopted and the tools were considered isothermal during the process.

The induction heating system was considered only in the vicinity of the blank top surface (face inductor) and was assumed that the surface was uniformly exposed to the current induced by the coil. Therefore, the skin depth region was located immediately below the top surface with a constant thickness. Furthermore, in order to analyse the influence of the skin-effect, two different frequencies for the power source were selected, 20 and $10 \mathrm{kHz}$. These frequencies correspond to skin depths of 0.82 and $1.16 \mathrm{~mm}$, respectively. The skineffect has a pronounced effect for aluminium alloys due their magnetic properties. In fact, the aluminium and its alloys are included in the class of paramagnetic material that is known for a relative magnetic permeability slightly greater than 1 $\left(\mu_{r}>1\right)$ [24]; for this reason, it is interesting to study this effect.

For the direct resistance system the contact between the electrodes and the blank was assumed perfect, eliminating any thermal gradient in this area. This assumption does not interfere with the results due to the high conductivity and the low heat capacity of the material, which mitigates possible 
Fig. 3 Temperature distribution in the specimen and grips for the heating process using a Gleeble system (complete model)

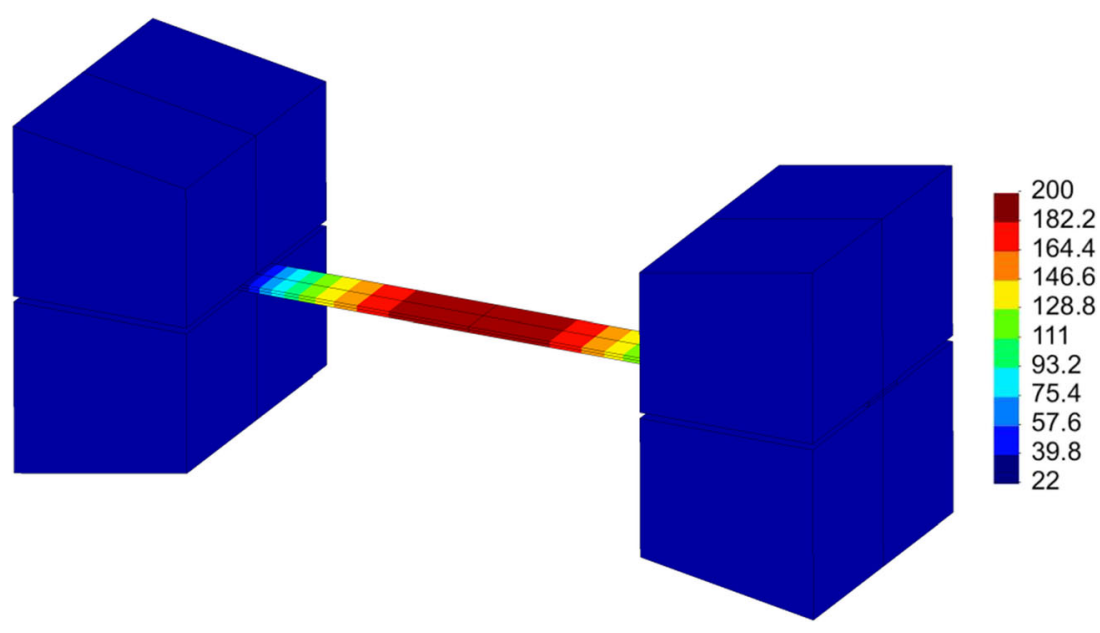

thermal gradients resulting from the defective contact between the blank and the electrodes.

Since the induction and direct resistance heating processes are typically carried out at ambient temperature, the finite element model considers the heat loss by convection to the environment. A convection coefficient of $40 \mathrm{~W} / \mathrm{m}^{2} /{ }^{\circ} \mathrm{C}$ and a temperature of $22{ }^{\circ} \mathrm{C}$ were used. The heating of the blank inside the forming tools requires a more complex approach to model the convection phenomenon. Figure 7 presents a schematically representation of the tools geometry, showing the region delimited by the tools, which is subject to heat loses for the environment. Although this interior area is identical for the top and bottom surface of the blank, the heat loss rates are different due to the favourable situation of the top surface for buoyancy force moving the air from the surface. Thus, different convection coefficients were determined for the top and bottom surface of the blank, based on the empirical equations determined by Lloyd et al. [48]:

$h_{\text {top }}=\left(0.15 R a_{L}^{\frac{1}{3}}\right) \frac{k}{L}$,

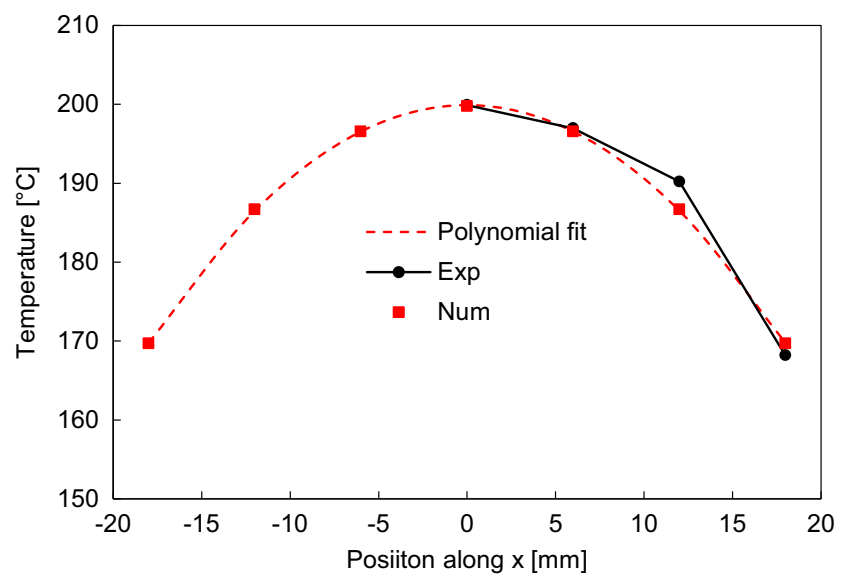

Fig. 4 Comparison between experimental and numerical temperature distributions along the specimen length $h_{\text {bott }}=\left(0.52 R a_{L}^{\frac{1}{5}}\right) \frac{k}{L}$,

where $R a_{L}$ is the Rayleigh number calculated for the properties of the air evaluated at $22{ }^{\circ} \mathrm{C}$ (temperature assumed for the environment). The convection coefficients determined with Eqs. (27) and (28) were $9.06 \mathrm{~W} / \mathrm{m}^{2} /{ }^{\circ} \mathrm{C}$ for the top surface and $2.31 \mathrm{~W} / \mathrm{m}^{2} /{ }^{\circ} \mathrm{C}$ for the bottom surface.

\subsubsection{Results and discussion}

Figure 8 presents the thermal response of the blank for each heating process (furnace, induction and direct resistance systems). Since a uniform temperature field was observed along the process for these three heating systems, the temperature evolution was collected on the centre of the blank (point B in Fig. 6). This is a consequence of the high thermal conductivity and low heat capacity of the aluminium blank. The results confirm that the use of a furnace in these conditions is the most time consuming option, due to the heat transfer mechanism inherent to this heating system. The other two systems are more efficient, but it has to be highlighted that direct

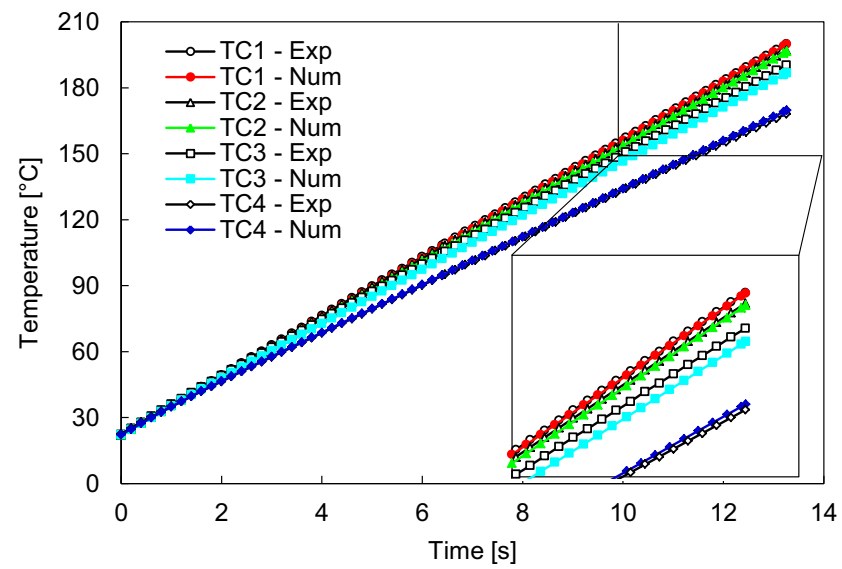

Fig. 5 Temperature evolution measured experimentally (thermocouples) and calculated with the numerical model 


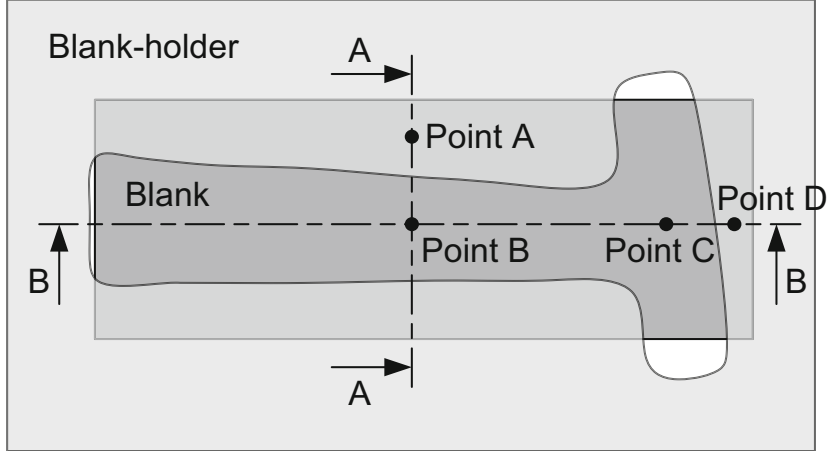

Fig. 6 Scheme of the modified blank shape used in the automotive Bpillar forming

resistance presented the highest heating rate. The decline on efficiency of the induction system was caused by the increase of frequency. The skin-effect is an important drawback inherent to the system and its control is important to minimize the loss of efficiency. It has to be mentioned that the heat loss for the environment in the direct resistance and induction systems was relative less importance than the heat supplied by the systems, causing irrelevant losses for the system efficiency.

The distribution of temperature on the blank heated by the forming tools is presented in Fig. 9 for different time instants. As expected, the area of the blank in contact with the forming tools shows the higher temperatures. This is highlighted in Figs. 10 and 11, which present the temperature distribution for the nodes located in section AA and section BB (Fig. 6), respectively. The area which was not in contact with the tools shows the lowest temperatures, revealing that the heat losses for the environment are very important for this specific heating method. The temperature evolution for the points A, $\mathrm{B}, \mathrm{C}$ and $\mathrm{D}$ (see Fig. 6) is presented in Fig. 12. The temperature difference between the points $\mathrm{C}$ and $\mathrm{A}$, evaluated in the final instant of the process when the stationary temperature distribution was achieved, was about $30^{\circ} \mathrm{C}$. Therefore, when

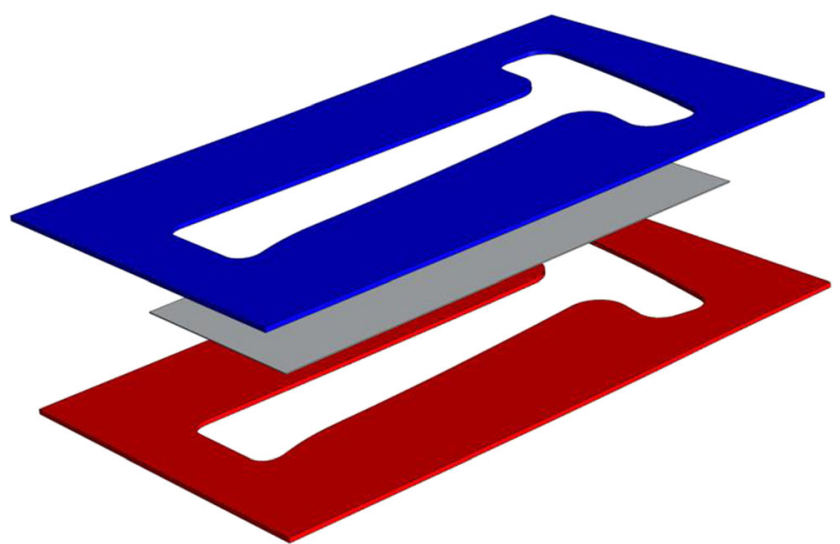

Fig. 7 Scheme of the area of the forming tools (die and blank-holder) in contact with the blank during the heating phase

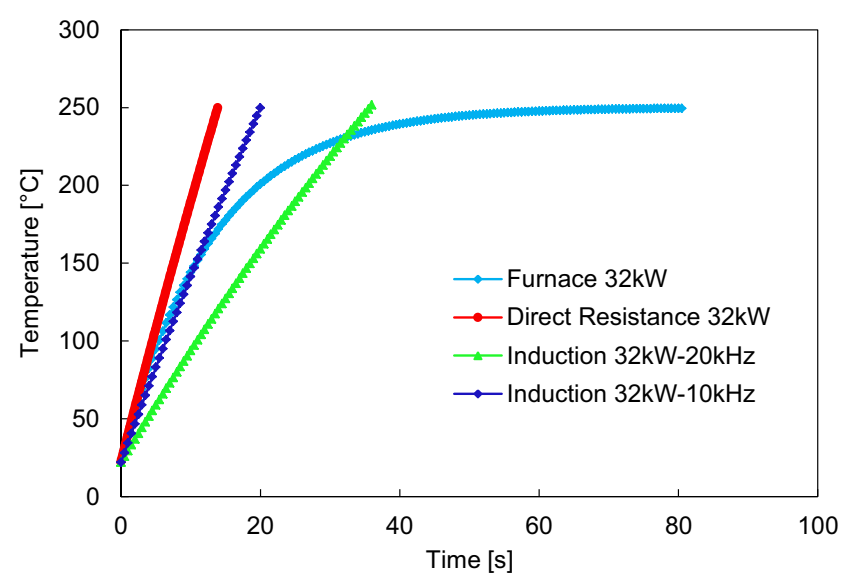

Fig. 8 Comparison of the blank temperature evolution for different heating processes: furnace, direct resistance system and induction system with different frequencies

using this heating method it can be important to model the heating phase, in order to take into account the thermal gradients observed. However, these thermal gradients can be experimentally avoided if the process elapses with the entire blank isolated in a temperature-controlled environment.

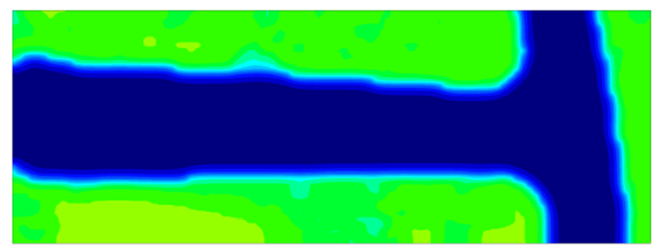

(a)

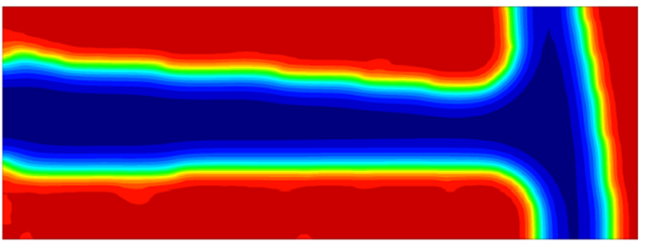

250

224.67

199.33

174

(b)

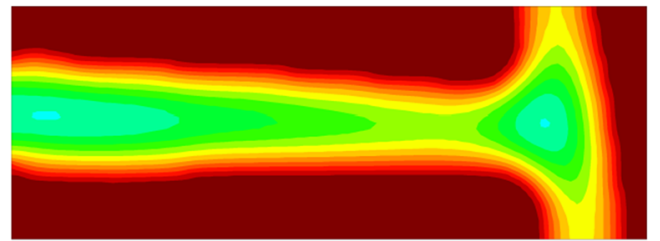

148.67

123.33

98

72.667

47.333

22

(c)

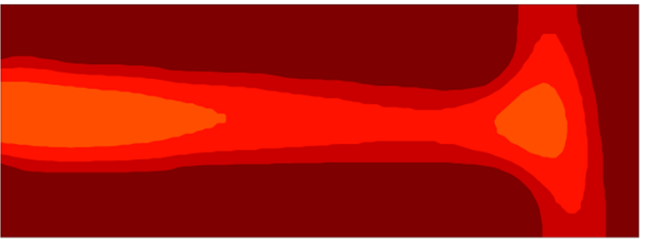

(d)

Fig. 9 Distribution of the blank temperature predicted by the numerical model at different instants: a 2 s; b 4 s; c 42 s; d 122 s 


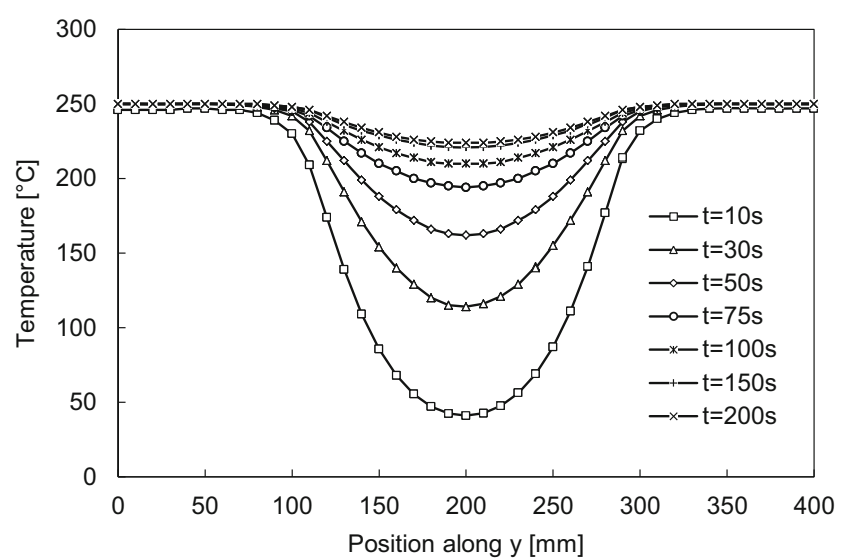

Fig. 10 Evolution of the blank temperature predicted by the numerical model for the section AA

\subsubsection{Temperature distribution after the transport for external heating methods}

After the heating phase, the external heating methods require a subsequent transport phase from the heating equipment to the press. This transport operation is not standardized and has a duration that depends of the set-up. Hence, it is interesting to verify the response of the heated blank to boundary conditions expected for this phase. For numerical simulation of the transport phase it was only considered the heat loss for the environment, neglecting any possible losses resulting from the contact with the carrying tools. Thus, only a convection term was considered for the boundary conditions. A convection heat transfer coefficient of $40 \mathrm{~W} / \mathrm{m}^{2} /{ }^{\circ} \mathrm{C}$ and a temperature of $22^{\circ} \mathrm{C}$ were assumed in order to simulate the air-cooling effect.

The heating and the transport phase were performed in a single simulation process. This allowed to consider the temperature field of the heating phase as initial condition for the transient thermal problem of the transport phase. The temperature gradients within the blank may be neglected, because the conduction resistance is small compared with the resistance to

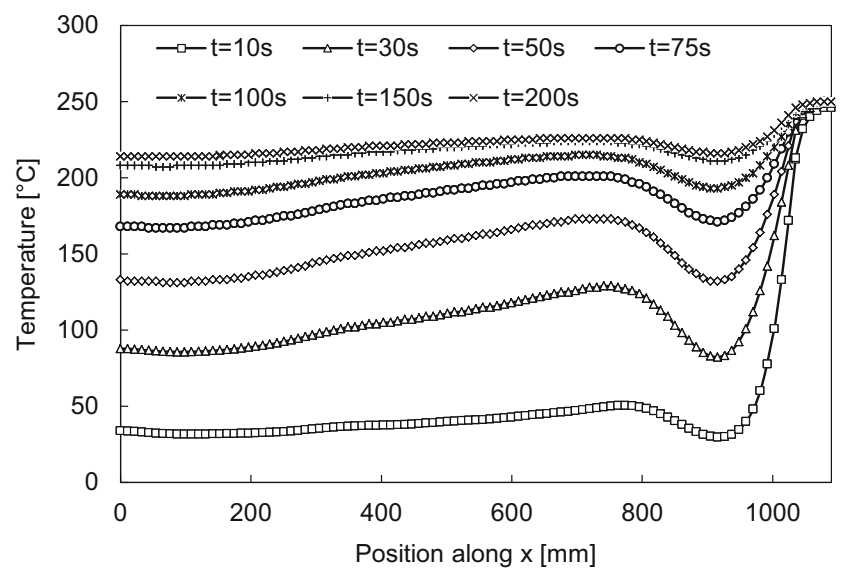

Fig. 11 Evolution of the blank temperature predicted by the numerical model for the section BB

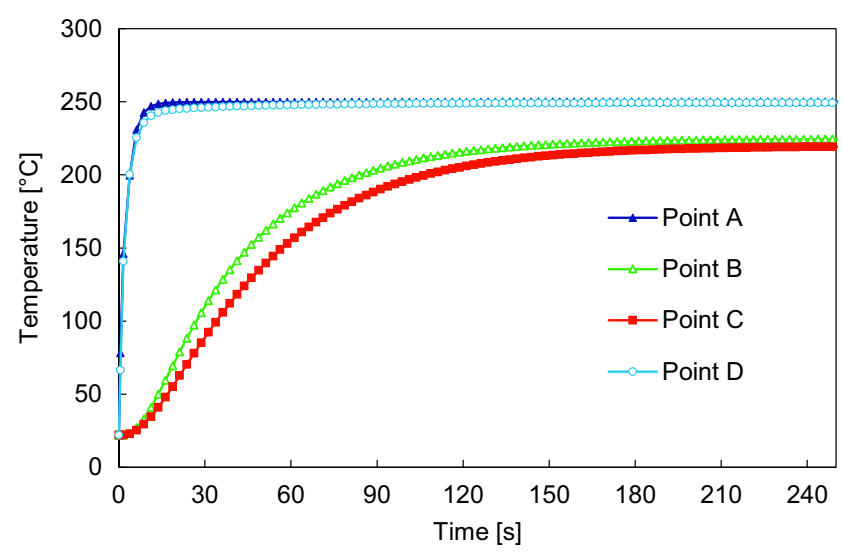

Fig. 12 Temperature evolution for the points $\mathbf{a}, \mathbf{b}, \mathbf{c}$ and $\mathbf{d}$ illustrated in Fig. 6

heat transfer between the blank and the surrounding air. Based on that, the temperature on the blank can be determined using the lumped capacitance method [49], which allows the determination of the temperature within the blank:

$T=T_{\infty}+\left(T_{\mathrm{i}}-T_{\infty}\right) \exp \left(-\frac{h_{\text {conv }} A_{\mathrm{s}}}{\rho c V} t\right)$,

based on the initial temperature $T_{i}$ and on the area of the blank surface exposed to the air $A_{\mathrm{s}}$.

The evolution of blank temperature only for the transport phase is presented in Fig. 13, evaluated by finite element method (numerical) and by Eq. (29) (analytical). The numerical results are in very good agreement with the analytical ones, which indicate a reduction of about $13{ }^{\circ} \mathrm{C}$ after $7 \mathrm{~s}$ of exposure time to the conditions aforementioned. This reveals that heat losses during the transport process should be considered, when a material with temperature-dependent properties is considered in a forming process simulation. The assumption of imposed temperature as the exact temperature before the deformation process can be a source of inaccuracies, compromising posterior results.

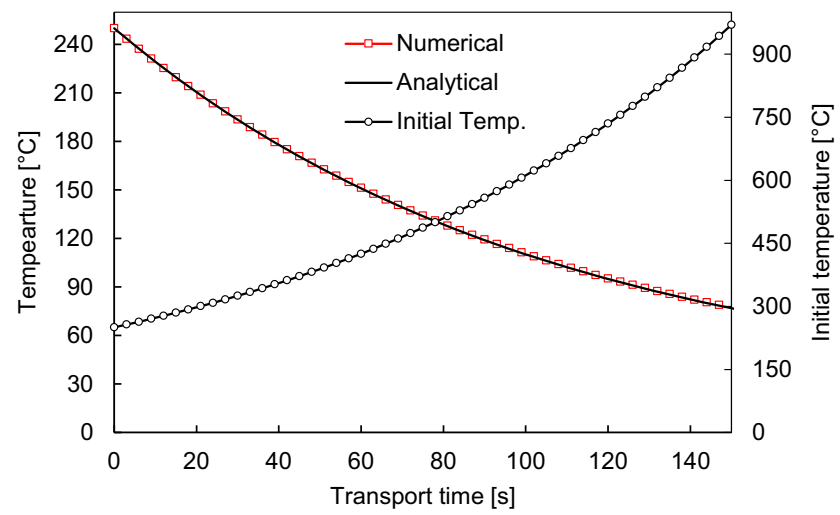

Fig. 13 Decreasing blank temperature during the transport phase and initial temperature required to assure a final temperature of $250{ }^{\circ} \mathrm{C}$ after the transport phase 
In the warm forming process set-up, this heat loss could be compensated with an overheating. However, it has to be mentioned that the increase of temperature during the heating phase can be detrimental for the material. Therefore, it would be necessary to determine accurately the precise time for the transport phase, before calculating the overheating needed to achieve the exact warm forming temperature, for the time instant before the start of the deformation. In order to balance the heat loss during the transport phase, the initial temperature to assure $250{ }^{\circ} \mathrm{C}$ after the transport phase can be determined. This can be done by solving Eq. (29) for the variable $T_{\mathrm{i}}$. The initial temperature to assure $250{ }^{\circ} \mathrm{C}$ after the transport phase is also presented in Fig. 13, taking into account the transport time.

\section{Conclusions}

This paper presents a summary of a finite element formulation, developed to simulate the heating and transport phases involved in warm sheet metal forming processes. An analysis of the state-of-art heating methods was presented, including temperature distribution and the heating time necessary to achieve the warm forming temperature. This analysis reveals abrupt thermal gradients for the blank heating inside the tools in the end of the process, which are usually ignored in the forming simulation process. For the external heating methods, the furnace was the most time-consuming process. However, if the objective is to achieve a uniform temperature this heating system as well as the others external systems are the best options. The transport phase for the external heating methods was also studied revealing that high heat losses occur in the initial instants of this phase, which could be balanced with an overheating. Nevertheless, a preliminary analysis is necessary to evaluate possible detrimental effects on the material, resulting from the overheating.

A novel algorithm for the prediction of thermal fields observed in a specimen tested on Gleeble system was presented. The results from the finite element model were compared with experimental results. Despite the several simplifications assumed in the model, the numerical and experimental results were found to be in agreement.

\footnotetext{
Acknowledgments The authors gratefully acknowledge the financial support of the Portuguese Foundation for Science and Technology (FCT) under project PTDC/EMS-TEC/1805/2012 and by FEDER funds through the program COMPETE-Programa Operacional Factores de Competitividade, under the project CENTRO-07-0224-FEDER-002001 (MT4MOBI). The authors would like to thank Prof. A. Andrade-Campos for helpful contributions on the development of the finite element code presented in this work.
}

\section{References}

1. González Palencia JC, Furubayashi T, Nakata T (2012) Energy use and $\mathrm{CO}_{2}$ emissions reduction potential in passenger car fleet using zero emission vehicles and lightweight materials. Energy 48:548565. doi:10.1016/j.energy.2012.09.041

2. Hirsch J (2014) Recent development in aluminium for automotive applications. Trans Nonferrous Met Soc Chin 24:1995-2002. doi: 10.1016/S1003-6326(14)63305-7

3. Kulekci MK (2007) Magnesium and its alloys applications in automotive industry. Int J Adv Manuf Technol 39:851-865. doi:10. 1007/s00170-007-1279-2

4. Toros S, Ozturk F, Kacar I (2008) Review of warm forming of aluminum-magnesium alloys. J Mater Process Technol 207:1-12. doi:10.1016/j.jmatprotec.2008.03.057

5. Kurukuri S, van den Boogaard AH, Miroux A, Holmedal B (2009) Warm forming simulation of Al-Mg sheet. J Mater Process Technol 209:5636-5645. doi:10.1016/j.jmatprotec.2009.05.024

6. Ghosh M, Miroux A, Werkhoven RJ et al (2014) Warm deepdrawing and post drawing analysis of two $\mathrm{Al}-\mathrm{Mg}-\mathrm{Si}$ alloys. J Mater Process Technol 214:756-766. doi:10.1016/j.jmatprotec. 2013.10.020

7. Abedrabbo N, Pourboghrat F, Carsley J (2007) Forming of AA5182-O and AA5754-O at elevated temperatures using coupled thermo-mechanical finite element models. Int J Plast 23:841-875. doi:10.1016/j.ijplas.2006.10.005

8. Laurent H, Coër J, Manach PY et al (2015) Experimental and numerical studies on the warm deep drawing of an $\mathrm{Al}-\mathrm{Mg}$ alloy. Int $\mathrm{J}$ Mech Sci 93:59-72. doi:10.1016/j.ijmecsci.2015.01.009

9. Grèze R, Manach PY, Laurent $H$ et al (2010) Influence of the temperature on residual stresses and springback effect in an aluminium alloy. Int J Mech Sci 52:1094-1100. doi:10.1016/j.ijmecsci.2010. 04.008

10. Coër J, Manach PY, Laurent H et al (2013) Piobert-Lüders plateau and Portevin-Le Chatelier effect in an Al-Mg alloy in simple shear. Mech Res Commun 48:1-7. doi:10.1016/j.mechrescom.2012.11. 008

11. Ghaffari Tari D, Worswick MJ, Winkler S (2013) Experimental studies of deep drawing of AZ31B magnesium alloy sheet under various thermal conditions. J Mater Process Technol 213:13371347. doi:10.1016/j.jmatprotec.2013.01.028

12. Hung N, Marion M (2012) Improved formability of aluminum alloys using laser induced hardening of tailored heat treated blanks. Phys Procedia 39:318-326. doi:10.1016/j.phpro.2012.10.044

13. Larsson L (2005) Warm sheet metal forming with localized in-tool induction heating. Lund University

14. Hasanuzzaman M, Rahim NA, Hosenuzzaman M et al (2012) Energy savings in the combustion based process heating in industrial sector. Renew Sustain Energy Rev 16:4527-4536. doi:10. 1016/j.rser.2012.05.027

15. Zhao PJ, Chen ZH, Dong CF (2014) Failure analysis of warm stamping of magnesium alloy sheet based on an anisotropic damage model. J Mater Eng Perform 23:4032-4041. doi:10.1007/s11665014-1214-2

16. Harrison NR, Ilinich A, Friedman PA, et al. (2013) Optimization of high-volume warm forming for lightweight sheet

17. Menezes LF, Teodosiu C (2000) Three-dimensional numerical simulation of the deep-drawing process using solid finite elements. J Mater Process Technol 97:100-106. doi:10.1016/S0924-0136(99) 00345-3

18. Oliveira MC, Alves JL, Menezes LF (2008) Algorithms and strategies for treatment of large deformation frictional contact in the numerical simulation of deep drawing process. Arch Comput Methods Eng 15:113-162. doi:10.1007/s11831-008-9018-x 
19. Kolleck R, Veit R, Merklein M et al (2009) Investigation on induction heating for hot stamping of boron alloyed steels. CIRP Ann Manuf Technol 58:275-278. doi:10.1016/j.cirp.2009.03.090

20. Takuda H, Mori K, Masuda I et al (2002) Finite element simulation of warm deep drawing of aluminium alloy sheet when accounting for heat conduction. J Mater Process Technol 120:412-418. doi:10. 1016/S0924-0136(01)01180-3

21. Lade J, Banoth BN, Gupta AK, Singh SK (2014) Metallurgical studies of austenitic stainless steel 304 under warm deep drawing. J Iron Steel Res Int 21:1147-1151. doi:10.1016/S1006-706X(14) 60197-7

22. Koh Y, Kim D, Seok D et al (2015) Characterization of mechanical property of magnesium AZ31 alloy sheets for warm temperature forming. Int J Mech Sci 93:204-217. doi:10.1016/j.ijmecsci.2015. 02.001

23. Krajewski PE (2001) Elevated temperature forming of sheet magnesium alloys

24. Rudnev V, Loveless D, Cook RL, Black M (2002) Handbook of induction heating. CRC Press, Boca Raton

25. Codrington J, Nguyen P, Ho SY, Kotousov A (2009) Induction heating apparatus for high temperature testing of thermomechanical properties. Appl Therm Eng 29:2783-2789. doi:10. 1016/j.applthermaleng.2009.01.013

26. Takuda H, Morishita T, Kinoshita T, Shirakawa N (2005) Modelling of formula for flow stress of a magnesium alloy AZ31 sheet at elevated temperatures. J Mater Process Technol 164-165: 1258-1262. doi:10.1016/j.jmatprotec.2005.02.034

27. Pellegrini D, Ghiotti A, Bruschi S (2011) Effect of warm forming conditions on AZ31B flow behaviour and microstructural characteristics. Int J Mater Form 4:155-161. doi:10.1007/s12289-010$1025-4$

28. Mori K (2012) Smart hot stamping of ultra-high strength steel parts. Trans Nonferrous Met Soc Chin 22:s496-s503. doi:10.1016/ S1003-6326(12)61752-X

29. Mori K, Maki S, Tanaka Y (2005) Warm and hot stamping of ultra high tensile strength steel sheets using resistance heating. CIRP Ann - Manuf Technol 54:209-212. doi:10.1016/S0007-8506(07)600857

30. Das S, Barekar N, El Fakir O et al (2015) Influence of intensive melt shearing on subsequent hot rolling and the mechanical properties of twin roll cast AZ31 strips. Mater Lett 144:54-57. doi:10. 1016/j.matlet.2015.01.017

31. Coër J, Bernard C, Laurent $\mathrm{H}$ et al (2011) The effect of temperature on anisotropy properties of an aluminium alloy. Exp Mech 51: 1185-1195. doi:10.1007/s11340-010-9415-6

32. Doege E, Dröder K (2001) Sheet metal forming of magnesium wrought alloys - formability and process technology. J Mater Process Technol 115:14-19. doi:10.1016/S0924-0136(01)00760-9

33. Palumbo G, Sorgente D, Tricarico L et al (2007) Numerical and experimental investigations on the effect of the heating strategy and the punch speed on the warm deep drawing of magnesium alloy AZ31. J Mater Process Technol 191:342-346. doi:10.1016/j. jmatprotec.2007.03.095

34. Lee YS, Kim MC, Kim SW et al (2007) Experimental and analytical studies for forming limit of AZ31 alloy on warm sheet metal forming. J Mater Process Technol 187-188:103-107. doi:10.1016/ j.jmatprotec.2006.11.118

35. Bathe KJ (1996) Finite element procedures. Prentice-Hall, Englewood Cliffs

36. Rodrigues JMC, Martins PAF (2002) Finite element modelling of the initial stages of a hot forging cycle. Finite Elem Anal Des 38: 295-305. doi:10.1016/S0168-874X(01)00065-8

37. Zhu J, Taylor ZRL, Zienkiewicz OC (2005) The finite element method: its basis and fundamentals. Butterworth-Heinemann

38. Hughes TJR (2012) The finite element method: linear static and dynamic finite element analysis. Courier Corporation

39. Madoliat R, Ghasemi A (2008) Inverse finite element formulations for transient heat conduction problems. Heat Mass Transf 44:569 577. doi:10.1007/s00231-007-0270-7

40. Vaz Jr M (2000) Simulação de problemas de acoplamento termomecânico

41. Menezes LF, Neto DM, Oliveira MC, Alves JL (2011) Improving computational performance through HPC techniques: case study using DD3IMP in-house code. AIP Conf Proc 1353:1220-1225. doi:10.1063/1.3589683

42. Andrade-Campos A, da Silva F, Teixeira-Dias F (2007) Modelling and numerical analysis of heat treatments on aluminium parts. Int J Numer Methods Eng 70:582-609. doi:10.1002/nme.1905

43. Xing HL, Makinouchi A (2002) FE modeling of thermo-elastoplastic finite deformation and its application in sheet warm forming. Eng Comput 19:392-410. doi:10.1108/02644400210430172

44. Stratton JA (1941) Electromagnetic theory. McGraw-Hill, New York

45. Zinn S, Semiatin SL (1988) Elements of induction heating

46. Kardoulaki E, Lin J, Balint D, Farrugia D (2014) Investigation of the effects of thermal gradients present in Gleeble high-temperature tensile tests on the strain state for free cutting steel. J Strain Anal Eng Des 49:521-532. doi:10.1177/0309324714531950

47. Numisheet 2008 (2008) The Numisheet Benchmark Study, Benchmark Problem BM03

48. Lloyd JR, Moran WR (1974) Natural convection adjacent to horizontal surface of various planforms. J Heat Transfer 96:443-447

49. Incropera FP (2011) Fundamentals of heat and mass transfer. Wiley, Canada

50. Kim HS, Koç M (2008) Numerical investigations on springback characteristics of aluminum sheet metal alloys in warm forming conditions. J Mater Process Technol 204:370-383. doi:10.1016/j. jmatprotec.2007.11.059 